\title{
Neighbourhood food environments: are they associated with adolescent dietary intake, food purchases and weight status?
}

\author{
Melissa N Laska ${ }^{1, *}$, Mary $\bigcirc$ Hearst $^{1}$, Ann Forsyth ${ }^{2}$, Keryn E Pasch ${ }^{3}$ and Leslie Lytle ${ }^{1}$ \\ 'Division of Epidemiology and Community Health, University of Minnesota, 1300 South 2nd Street, WBOB Suite \\ 300, Minneapolis, MN 55454, USA: ${ }^{2}$ Department of City and Regional Planning, Cornell University, Ithaca, \\ NY, USA: ${ }^{3}$ Department of Kinesiology and Health Education, University of Texas at Austin, Austin, TX, USA
}

Submitted 1 December 2009: Accepted 22 April 2010: First published online 8 June 2010

\begin{abstract}
Objective: To examine neighbourhood food environments, adolescent nutrition and weight status.

Design: Cross-sectional, observational study.

Setting: Minneapolis/St. Paul metropolitan region, Minnesota, USA.

Subjects: A total of 349 adolescents were recruited to the study. Participants completed $24 \mathrm{~h}$ dietary recalls and had their weight and height measured. They also reported demographic information and other diet-related behaviours. Geographic Information Systems were used to examine the availability and proximity of food outlets, particularly those captured within the 800, 1600 and/or $3000 \mathrm{~m}$ network buffers around participants' homes and schools.

Results: Adjusting for gender, age and socio-economic status, adolescents' sugarsweetened beverage intake was associated with residential proximity to restaurants (including fast food), convenience stores, grocery stores and other retail facilities within the 800 and/or $1600 \mathrm{~m}$ residential buffers $(P \leq 0 \cdot 01)$. BMI $Z$-score and percentage body fat were positively associated with the presence of a convenience store within a $1600 \mathrm{~m}$ buffer. Other individual-level factors, such as energy, fruit and vegetable intake, as well as convenience store and fast food purchasing, were not significantly associated with features of the residential neighbourhood food environment in adjusted models. In addition, school neighbourhood environments yielded few associations with adolescent outcomes.

Conclusions: Many factors are likely to have an important role in influencing adolescent dietary intake and weight status. Interventions aimed at increasing neighbourhood access to healthy foods, as well as other approaches, are needed.
\end{abstract}

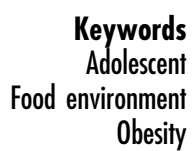

Obesity
Neighbourhood environments may influence various health behaviours, including dietary intake. A recent literature review highlighted numerous studies reporting that greater access to neighbourhood grocery stores was associated with better dietary intake and lower obesity rates among adults ${ }^{(1)}$. In contrast, greater access to convenience stores and restaurants, including fast food, has been associated with less favourable diet quality and increased obesity, although the findings are not consistent ${ }^{(2)}$. The distribution of food stores and inequities in access to healthy foods may be a particular concern in the $\mathrm{USA}^{(3)}$ and has been widely cited as a promising target for large-scale public health interventions addressing obesity and healthy eating ${ }^{(4)}$.

To date, many studies have focused on adults, with less attention on youth ${ }^{(5,6)}$. Given that adolescence is marked by increasing independence over decisions including what to eat, where to go and how to spend money, this may be an important age during which food access affects dietary choices. Although studies among adults have focused primarily on residential access to food outlets, other studies highlight the proliferation of fast food and other food outlets around schools ${ }^{(7-9)}$. Thus, it is important to consider neighbourhoods surrounding both homes and schools to more fully understand environmental influences on youth. In addition, distinguishing between the dose of environmental exposure (i.e. the density of food stores or the number of food stores contained within a given area around one's home or school) $v$. access (i.e. proximity or distance to the nearest food store) remains poorly understood in this population.

The purpose of the present study was to examine the extent to which food outlet proximity and density, particularly around adolescents' homes and schools, was associated with dietary intake, food purchases and weight status. 


\section{Methods}

Adolescents and one parent ( $n 349$ pairs) from the Minneapolis/St. Paul metropolitan area were recruited for participation in the Identifying Determinants of Eating and Activity Study, as described in detail elsewhere ${ }^{(10)}$.

\section{Neigbbourbood-level measures}

Geographic Information Systems (GIS) data were used to calculate the distance to and density of food outlets around the participants' homes and schools. Food outlets included all restaurants (including fast food), convenience stores, grocery stores and any retail facilities identified using NAICS (North American Industry Classification System) codes, a common tool in this type of research for identifying business types ${ }^{(11)}$. Purchased Dun and Bradstreet 2006 business data provided food outlet addresses. Automated geocoding resulted in 78-88\% of addresses being matched to GIS street databases for various types of stores; after extensive proofing of addresses using Internet and phone databases, this was raised to 94-100\%, depending on store type. Errors in addresses included incorrect zip codes, street numbers not in street database, word order problems, inconsistent abbreviations and typographical errors. These methods are described in detail elsewhere ${ }^{(12)}$. Network distances were calculated measuring distance from the participant's home or school to food outlets along a street network using ArcGIS version 9 (ESRI, Redlands, CA, USA). Densities (number of stores within a specified buffer) were calculated in network buffer distances by dividing total neighbourhood food outlets by land area. For our purposes, we examined 800, 1600 and $3000 \mathrm{~m}$ buffers ( 0.5, 1 and 2 miles, respectively) to be consistent with previous study and maximize variability within this sample's largely suburban geography.

\section{Youth-level measures}

Adolescents completed telephone-administered $24 \mathrm{~h}$ dietary recalls. Multiple dietary recalls are widely accepted as valid and reliable for dietary assessment, yielding acceptable validity in youth ${ }^{(13)}$. Trained staff from the Nutrition Coordination Center (University of Minnesota) administered the recalls, using the Nutrition Data System for Research and a multiple-pass method ${ }^{(14)}$. Three days of dietary recalls were obtained when possible, although only $2 \mathrm{~d}$ of data were obtained in a limited number of cases. Energy intake was examined for possible outliers $(<2092 \mathrm{~kJ} / \mathrm{d}(500 \mathrm{kcal} / \mathrm{d}),>20920 \mathrm{~kJ} / \mathrm{d}(5000 \mathrm{kcal} / \mathrm{d}))$ as per standard procedures ${ }^{(15)}$; no outliers were identified.

Adolescents' reported factors related to demographics and energy balance. Fast food and convenience store food purchases were assessed by asking: (i) 'In the past month ... how many times did you buy food at a restaurant where food is ordered at a counter or at a drive-through window (there is no waiter/waitress)?' and (ii) 'How many times did you buy food at a convenience store, gas station, hardware store or a vending machine, outside of school?' Nine response options ranged from never to $\geq 3$ times/d. Item reliability and validity have been published elsewhere ${ }^{(16)}$.

Adolescents' weight and height were measured wearing light clothing. Trained staff assessed height using a Shorr height board (Irwin Shorr, Olney, MD, USA), and weight and body composition using a Tanita scale, a bioelectrical impedance device (TBF-300A Body Composition Analyzer; Tanita, Arlington Heights, IL, USA). BMI $Z$-scores were calculated using the US Centers for Disease Control and Prevention growth charts ${ }^{(17)}$.

Geocoded addresses and participant data were merged with US Census 2000 tract-level data. Median household income was chosen to account for area-level socio-economic status (SES). The percentageage of students receiving free or reduced-cost lunch accounted for school-level SES.

\section{Analysis}

Given the highly skewed distribution of the GIS-derived residential data (i.e. substantial number of buffers without food outlets of any given type, most likely due to zoning regulations restricting commercial land use within residential areas), we dichotomized density measures into the presence $v$. absence of facilities within specified network buffers. School-level density measures for 1600 and $3000 \mathrm{~m}$ buffers were more normally distributed (skewness $<2 \cdot 00$ ), with a majority of school-level buffers (98\%) containing at least one food outlet; therefore, these were modelled as continuous variables. Given that measures of distance and density reflect unique constructs, both types of measures were included in the analytic phase.

We employed a two-stage analytical approach ${ }^{(11)}$. First, we examined unadjusted associations between GISderived and diet- or weight-related variables (outlined in Table 1). For only those yielding significant associations $(P \leq 0 \cdot 05)$, we examined adjusted models, controlling for parental education, adolescent sex, age, school-level and area-level SES. In adjusted models, we used a $P \leq 0 \cdot 01$ threshold to indicate statistical significance. We used this somewhat conservative approach to account for the many possible associations that could be examined and are typical in this type of research. In addition, interpretation of these results sought to identify robust patterns in findings across various features, rather than individual associations between specific variables. Adjusted models were generated using the SAS statistical software package version 9.1 for Windows (SAS Institute Inc., Cary, NC, USA) PROC GENMOD procedure using compound symmetry variance structure for generalized estimating equations with schools modelled as a random effect because the study recruitment approach resulted in clustering within schools. Identical models were run using PROC GLM to calculate $r^{2}$ statistics. Point estimates were similar between the two procedures. 
Table 1 Descriptive statistics of the study sample

\begin{tabular}{|c|c|c|c|c|}
\hline & Mean or \% & SD & Minimum & Maximum \\
\hline \multicolumn{5}{|l|}{ Sociodemographic characteristics ( $n$ 334) } \\
\hline Age (years) & $15 \cdot 4$ & $1 \cdot 7$ & $10 \cdot 8$ & $17 \cdot 7$ \\
\hline Median household income (based on Census tract) & $\$ 76790$ & $\$ 18006$ & $\$ 31691$ & $\$ 147640$ \\
\hline (1) & $49 \cdot 1$ & & & \\
\hline Parents with at least college education (\%) & $64 \cdot 4$ & & & \\
\hline \multicolumn{5}{|l|}{ Dependent variables } \\
\hline \multicolumn{5}{|l|}{ Dietary intake, via multiple $24 \mathrm{~h}$ recalls $(n 316)^{\star}$} \\
\hline Average daily energy intake $(\mathrm{kcal}) \dagger$ & 2066 & 696 & 585 & 4559 \\
\hline Average daily fat intake (\%) & $30 \cdot 8$ & $5 \cdot 4$ & $13 \cdot 1$ & $45 \cdot 2$ \\
\hline Daily servings of fruit and vegetables & $2 \cdot 9$ & $1 \cdot 8$ & $0 \cdot 0$ & $11 \cdot 1$ \\
\hline Daily servings of vegetables only & $2 \cdot 3$ & $1 \cdot 6$ & 0.0 & $11 \cdot 1$ \\
\hline Average daily servings of sweetened soft drinks & 0.5 & $0 \cdot 8$ & $0 \cdot 0$ & $4 \cdot 2$ \\
\hline \multicolumn{5}{|l|}{ Food purchases, via survey self-report $(n 334)$} \\
\hline Weekly purchases at fast-food restaurants & 0.9 & 0.9 & $0 \cdot 0$ & $5 \cdot 5$ \\
\hline Weekly purchases at fast-food restaurants or convenience stores & 1.5 & $1 \cdot 4$ & $0 \cdot 0$ & $11 \cdot 0$ \\
\hline \multicolumn{5}{|l|}{ Objectively measured anthropometrics ( $n 340)$} \\
\hline BMI Z-score (based on CDC 2000 growth curves) & $0 \cdot 3$ & $1 \cdot 0$ & $-2 \cdot 5$ & $2 \cdot 7$ \\
\hline Percentage body fat & $20 \cdot 4$ & $10 \cdot 1$ & $3 \cdot 6$ & $59 \cdot 3$ \\
\hline \multicolumn{5}{|l|}{ Residential-level GIS-derived independent variables ( $n$ 334) } \\
\hline \multicolumn{5}{|l|}{ Distance to nearest facility (per $100 \mathrm{~m}) \ddagger$} \\
\hline Fast-food restaurant & $21 \cdot 2$ & $20 \cdot 9$ & $0 \cdot 2$ & $131 \cdot 0$ \\
\hline Any restaurant & $16 \cdot \overline{9}$ & $17 \cdot 0$ & $0 . \overline{0}$ & $115 \cdot 3$ \\
\hline Convenience store & $35 \cdot 1$ & $28 \cdot 3$ & $0 \cdot 0$ & $176 \cdot 7$ \\
\hline Grocery store & $27 \cdot 3$ & $23 \cdot 8$ & $1 \cdot 1$ & $144 \cdot 0$ \\
\hline \multicolumn{5}{|l|}{ Density: presence of a facility within $800 \mathrm{~m}$ street-network buffer (\%) } \\
\hline Fast-food restaurant & $21 \cdot 0$ & & & \\
\hline Any restaurant & $30 \cdot 5$ & & & \\
\hline Convenience store & $18 \cdot 6$ & & & \\
\hline Grocery store & $13 \cdot 8$ & & & \\
\hline Any retail store & $30 \cdot 5$ & & & \\
\hline \multicolumn{5}{|l|}{ Density: presence of a facility within $1600 \mathrm{~m}$ street-network buffer (\%) } \\
\hline Fast-food restaurant & $51 \cdot 2$ & & & \\
\hline Any restaurant & $63 \cdot 8$ & & & \\
\hline Convenience store & $49 \cdot 7$ & & & \\
\hline Grocery store & $37 \cdot 7$ & & & \\
\hline Any retail store & $66 \cdot 5$ & & & \\
\hline \multicolumn{5}{|l|}{ Density: presence of a facility within $3000 \mathrm{~m}$ street-network buffer (\%) } \\
\hline Fast-food restaurant & $80 \cdot 0$ & & & \\
\hline Any restaurant & $84 \cdot 7$ & & & \\
\hline Convenience store & $74 \cdot 0$ & & & \\
\hline Grocery store & $58 \cdot 7$ & & & \\
\hline Any retail store & $81 \cdot 1$ & & & \\
\hline \multicolumn{5}{|l|}{ School-level GIS-derived independent variables ( $n$ 277)§ } \\
\hline \multicolumn{5}{|l|}{ Distance to the nearest facility (per $100 \mathrm{~m}$ ) } \\
\hline Fast-food restaurant & $10 \cdot 3$ & $14 \cdot 5$ & $1 \cdot 3$ & $230 \cdot 6$ \\
\hline Any restaurant & $8 \cdot 6$ & $11 \cdot 2$ & $0 \cdot 0$ & 171.9 \\
\hline Convenience store & $25 \cdot 2$ & $22 \cdot 4$ & $2 \cdot 5$ & $274 \cdot 3$ \\
\hline Grocery store & $14 \cdot 9$ & $16 \cdot 6$ & $1 \cdot 0$ & $233 \cdot 0$ \\
\hline \multicolumn{5}{|l|}{ Density: presence of a facility within $800 \mathrm{~m}$ street-network buffer (\%) } \\
\hline Fast-food restaurant & $44 \cdot 4$ & & & \\
\hline Any restaurant & $54 \cdot 5$ & & & \\
\hline Convenience store & $42 \cdot 6$ & & & \\
\hline Grocery store & $28 \cdot 9$ & & & \\
\hline Any retail store & $65 \cdot 0$ & & & \\
\hline $\begin{array}{l}\text { Density of facilities within } 1600 \mathrm{~m} \text { street-network buffer (number of fa } \\
\text { per land area (hectare, excluding water)) }\end{array}$ & & & & \\
\hline Fast-food restaurant & 0.012 & 0.012 & 0.000 & $0 \cdot 140$ \\
\hline Any restaurant & 0.023 & 0.027 & 0.000 & 0.389 \\
\hline Convenience store & 0.004 & 0.004 & 0.000 & 0.019 \\
\hline Grocery store & 0.004 & 0.006 & 0.000 & 0.029 \\
\hline Any retail store & 0.017 & 0.014 & 0.000 & $0 \cdot 103$ \\
\hline $\begin{array}{l}\text { Density of facilities within } 3000 \mathrm{~m} \text { street-network buffer (number of fa } \\
\text { per land area (hectare, excluding water)) }\end{array}$ & & & & \\
\hline Fast-food restaurant & 0.008 & 0.006 & 0.000 & 0.059 \\
\hline Any restaurant & 0.018 & 0.016 & 0.000 & $0 \cdot 171$ \\
\hline Convenience store & 0.004 & 0.003 & 0.000 & 0.015 \\
\hline Grocery store & 0.003 & 0.004 & 0.000 & 0.023 \\
\hline Any retail store & 0.014 & 0.010 & 0.000 & 0.062 \\
\hline
\end{tabular}

GIS, Geographic Information System; CDC, US Centers for Disease Control and Prevention.

${ }^{*}$ Number of participants with data for at least 2-3 dietary recalls.

$\dagger 1 \mathrm{kcal}=4.184 \mathrm{~kJ}$.

fFor example, these results could be interpreted as the average distance to the nearest fast-food restaurant was $2100 \mathrm{~m}$ from the participants' homes.

§Includes participants with non-missing data for school-level free or reduced cost lunch and parent-reported level of education. 


\section{Results}

Mean participant age was 15 (range: 11-18) years, and $48.8 \%$ of the participants were male (Table 1 ). The sample was primarily Caucasian $(93.4 \%)$, reflecting the sampling region, which is $86 \cdot 1 \%$ whites overall ${ }^{(10)}$. Adolescents attended schools largely in suburban areas $(83.6 \%$ suburban and $16 \cdot 4 \%$ central city). Descriptive characteristics of adolescent dietary intake, food purchasing, weight status and body composition, as well as characteristics of the food environment around the participants' homes and schools, are also presented in Table 1.

\section{Neigbbourbood-and individual-level associations}

Significant adjusted estimates between individual adolescent characteristics (such as dietary intake and weight status) are presented in Table 2. Given that there was no significant association $(P>0 \cdot 01)$ between energy, dietary fat, fruit and vegetables, vegetables alone, or fast food and convenience store purchasing and GIS variables, these estimates are not presented.

Adjusted models indicate that sugar-sweetened beverage (SSB) intake was negatively associated with distance from home to the nearest restaurant $(\beta=-0 \cdot 007,95 \% \mathrm{CI}$ $-0.01,-0.003)$ or grocery store $(\beta=-0.005,95 \% \mathrm{CI}$ $-0 \cdot 01,-0 \cdot 001)$, with greater distance associated with less consumption. SSB consumption was also positively associated with food outlet density across a wide range of environmental measures, including having at least one fast-food restaurant, restaurant of any kind, convenience store, grocery store or any retail facility within a $1600 \mathrm{~m}$ residential network buffer, as well as the presence of a restaurant within $800 \mathrm{~m}$. Furthermore, BMI $Z$-score and percentage body fat were positively associated with the presence of a convenience store within a $1600 \mathrm{~m}$ residential buffer (BMI $Z$-score: $\beta=0 \cdot 26,95 \%$ CI $0 \cdot 05,0 \cdot 48$; percentage body fat: $\beta=2 \cdot 17,95 \%$ CI $0 \cdot 44,3 \cdot 91$ ). All of these models assessing individual-level associations with home neighbourhood environments had relatively small $r^{2}$ values $(0 \cdot 10-0 \cdot 13)$.

Only three school-level associations resulting from adjusted models were significant (data not shown). These included: (i) BMI $Z$-score being negatively associated with the presence of any restaurant within $800 \mathrm{~m}$ $\left(\beta=-0 \cdot 28,95 \%\right.$ CI $\left.-0 \cdot 50,-0 \cdot 07 ; r^{2}=0 \cdot 04\right)$; (ii) percentage body fat being negatively associated with the presence of a fast-food restaurant within $800 \mathrm{~m}(\beta=-2 \cdot 61,95 \%$ CI $-4 \cdot 58,-0 \cdot 64 ; r^{2}=0 \cdot 35$; and (iii) percentage body fat being negatively associated with the presence of any restaurant within $800 \mathrm{~m}\left(\beta=-3 \cdot 20,95 \% \mathrm{CI}-5 \cdot 17,-1 \cdot 23 ; r^{2}=0 \cdot 36\right)$. Although the percentage variance explained in these latter two models was notable, a vast majority of this

Table 2 Significant adjusted estimates from multi-level regression models modelling associations between residential and school neighbourhood characteristics and adolescent food intake or purchasing $(P \leq 0 \cdot 01)$

\begin{tabular}{|c|c|c|c|c|c|c|c|c|c|}
\hline & \multicolumn{3}{|c|}{$\begin{array}{l}\text { Sugar-sweetened beverage intake } \\
\qquad(n \text { 316) }\end{array}$} & \multicolumn{3}{|c|}{$\begin{array}{l}\text { BMI Z-score } \\
\quad(n \text { 334) }\end{array}$} & \multicolumn{3}{|c|}{$\begin{array}{l}\text { Percentage body fat } \\
\qquad(n 334)\end{array}$} \\
\hline & $\beta$ & $Z$ & $95 \% \mathrm{Cl}$ & $\beta$ & $Z$ & $95 \% \mathrm{Cl}$ & $\beta$ & $Z$ & $95 \% \mathrm{Cl}$ \\
\hline \multicolumn{10}{|l|}{ Fast-food restaurants* } \\
\hline Distance to the nearest facility (per $100 \mathrm{~m}$ ) & - & - & - & - & - & - & - & - & - \\
\hline Presence within $800 \mathrm{~m}$ & - & - & - & - & - & - & - & - & - \\
\hline Presence within $1600 \mathrm{~m}$ & $0 \cdot 25$ & $2 \cdot 51$ & $0.05,0.44$ & - & - & - & - & - & - \\
\hline Presence within $3000 \mathrm{~m}$ & - & - & - & - & - & - & - & - & - \\
\hline \multicolumn{10}{|l|}{ Any restaurants ${ }^{\star}$} \\
\hline Distance to the nearest facility (per $100 \mathrm{~m}$ ) & -0.007 & $-3 \cdot 38$ & $-0.01,-0.003$ & - & - & - & - & - & - \\
\hline Presence within $800 \mathrm{~m}$ & 0.28 & $2 \cdot 71$ & $0.08,0.48$ & - & - & - & - & - & - \\
\hline Presence within $1600 \mathrm{~m}$ & 0.23 & $2 \cdot 53$ & $0.05,0.41$ & - & - & - & - & - & - \\
\hline Presence within $3000 \mathrm{~m}$ & - & - & - & - & - & - & - & - & - \\
\hline \multicolumn{10}{|l|}{ Convenience stores ${ }^{*}$} \\
\hline Distance to the nearest facility (per $100 \mathrm{~m}$ ) & - & - & - & - & - & - & - & - & - \\
\hline Presence within $800 \mathrm{~m}$ & - & - & - & - & - & - & - & - & - \\
\hline Presence within $1600 \mathrm{~m}$ & $0 \cdot 24$ & $2 \cdot 66$ & $0.06,0.41$ & $0 \cdot 26$ & $2 \cdot 37$ & $0.05,0.48$ & $2 \cdot 17$ & $2 \cdot 45$ & $0.44,3.91$ \\
\hline Presence within $3000 \mathrm{~m}$ & - & - & - & - & - & - & - & - & - \\
\hline \multicolumn{10}{|l|}{ Grocery stores* } \\
\hline Distance to the nearest facility (per $100 \mathrm{~m}$ ) & -0.005 & $-2 \cdot 56$ & $-0.01,-0.001$ & - & - & - & - & - & - \\
\hline Presence within $800 \mathrm{~m}$ & - & - & - & - & - & - & - & - & - \\
\hline Presence within $1600 \mathrm{~m}$ & $0 \cdot 31$ & $3 \cdot 10$ & $0 \cdot 11,0.51$ & - & - & - & - & - & - \\
\hline Presence within $3000 \mathrm{~m}$ & - & - & - & - & - & - & - & - & - \\
\hline \multicolumn{10}{|l|}{ Any retail facilities* ${ }^{*}$} \\
\hline Presence within $800 \mathrm{~m}$ & - & - & - & - & - & - & - & - & - \\
\hline Presence within $1600 \mathrm{~m}$ & 0.24 & $2 \cdot 76$ & $0.07,0.41$ & - & - & - & - & - & - \\
\hline Presence within $3000 \mathrm{~m}$ & - & - & - & - & - & - & - & - & - \\
\hline
\end{tabular}

Models controlled for parent's education, adolescent's sex, age and median household income (at the census tract level) and accounted for clustering at the school level are included. Models utilizing data on sugar-sweetened beverage intake also included a covariate for number of days of recall data available (i.e. $2 v .3 \mathrm{~d})$. Only adjusted estimates that were statistically significant $(P \leq 0.01)$ are presented in the table. Dietary intake of energy, fat, fruit and vegetables and vegetables alone, as well as frequency of fast food/convenience purchases, yielded no significant associations with Geographic Information Systems variables in adjusted models, and thus are not presented.

*Generated using distance via street networks. 
variance was explained by the covariates in the model; when the GIS variables were removed from these models, $r^{2}$ was $0 \cdot 33$.

\section{Discussion}

Although many diet- and weight-related variables examined here were not consistently associated with neighbourhood food environments, SSB intake notably yielded a positive and robust association with the presence of food and non-food retail facilities in the 800 and $1600 \mathrm{~m}$ residential buffers. Proximity and access may influence adolescents' SSB consumption, given the convenience of these beverages, minimal cost and ubiquitous presence in a wide range of retail facilities. Findings from Wang et al. ${ }^{(18)}$ show that an average excess intake of $468-690 \mathrm{~kJ} / \mathrm{d}(110-165 \mathrm{kcal} / \mathrm{d})$ may account for the excess weight gain observed among US children over the past two decades. Thus, environmental factors contributing to the daily consumption of one additional SSB may be sufficient to promote long-term weight gain in a significant proportion of youth.

In contrast, we did not detect similar significant and robust associations between other dietary characteristics and features of the neighbourhood environment around the home. It is possible that much of our suburbanresiding sample may drive more than $3000 \mathrm{~m}$ to purchase food for home consumption, thus resulting in overall nutrient intake (e.g. energy or fat intake) having little association with local food availability.

BMI $Z$-score and percentage body fat yielded a moderate, positive association with the presence of convenience stores within $1600 \mathrm{~m}$ of the home. Although these findings were not particularly robust (i.e. yielding associations with a wide array of neighbourhood characteristics), they align well with two previous studies yielding similar results among youth ${ }^{(6,19)}$. Previous studies illustrate that convenience stores offer large proportions of highly processed, energy-dense foods, compared to other types of retail food outlets, and supermarkets offer a greater variety of more healthy foods ${ }^{(20,21)}$. Not all previous studies, however, have detected a relationship between these food outlet densities and childhood weight gain ${ }^{(22)}$, perhaps underscoring the complexities of the aetiology of obesity.

Although numerous characteristics of the school neighbourhood environment yielded significant associations with diet-related behaviours in unadjusted analyses, most of these relationships were no longer apparent after controlling for covariates. However, few schools in our sample had zero food outlets within the specified buffer areas, meaning that nearly all schools had some food outlet 'exposure'. Thus, it is possible that these schoollevel findings may be explained by the fact that the mere presence ( $v$. absence) of at least one food outlet within close proximity had a greater impact on dietary consumption than the sheer number or density of nearby food outlets. In addition, students in our largely suburban sample may be less influenced by these food outlets if they are bused or driven directly to school (rather than walking or taking public transit).

Paradoxically, the few findings that were significant in our analyses of school neighbourhood environments were in the opposite directions to those that had been hypothesized (i.e. BMI $Z$-score or percentage body fat was lower among those who were exposed to fast food and/or any restaurants within $800 \mathrm{~m}$ of their school). These findings are difficult to explain and may reflect a variety of exposures (in the neighbourhood, as well as schools, families and other realms of influence) in the lives of these young people. The present study required a large number of statistical tests, and although we accounted

for this by using relatively conservative procedures and $\alpha$ levels, these findings may reflect a statistical anomaly.

Overall, the specific impact of food outlet access on diet and weight remains somewhat unclear. Policy makers and key stakeholders are searching for guidance about how to positively affect dietary patterns, and additional research is needed to guide practice-based recommendations. Over the years, the implementation of nutrition education programmes has been logistically challenging, and impact has been limited. Thus, attention has turned towards changing the physical infrastructure as a means of addressing obesity. Numerous local governments have proposed changes to zoning, food licensing and other factors in hopes of improving healthy food availability and limiting access to less healthy foods ${ }^{(23)}$.

However, in addition to access, food choices also reflect an array of personal and social values. Although previous studies have reported associations between food access and diet-related factors, overall associations have been rather small in magnitude, with inconsistencies in findings between the USA and other international settings ${ }^{(3)}$. In fact, much of the US association between food access and obesity may be attributed to SES-based disparities in access, which have been widely documented $^{(1)}$. It is possible that in food-rich environments where access is unrestricted, social influences and personal preferences affect consumption more than physical environments ${ }^{(24)}$.

The present study had numerous strengths (e.g. using state-of-the-art dietary intake assessment and measured heights and weights) as well as limitations. The study was conducted only in one region of the USA and included a small, non-representative youth sample. The inherent limitations of GIS data, particularly with regard to describing food environments, are also well known ${ }^{(10,24)}$. Bader et $a l^{(25)}$ found that disagreements between data sources were not significantly correlated with influential covariates, such as SES, but still found substantial disagreements between sources (e.g. a 17.6\% disagreement between data sources as to whether a supermarket or 
grocery was present on a city block). Although commercial food business databases have limitations in data quality, we took extra effort to manually check and ensure the accuracy of addresses in our purchased data ${ }^{(12,26)}$.

Furthermore, the selection of an appropriate buffer size is a difficult issue that deserves additional attention in future studies ${ }^{(1)}$. Although most of the study on neighbourhood food environments has examined ecological associations between environmental factors and dietary intake, with relatively crude classifications of 'neighbourhoods' (e.g. exploring food store availability within Census tracts, zip codes or states), the studies that have used GIS buffers to more narrowly define the neighbourhood food environment have not employed a consistently defined buffer size. Buffer sizes have included $100 \mathrm{~m}^{(27)}, 1000 \mathrm{~m}^{(27)}, 0 \cdot 5^{(28,29)}, 1^{(29)}$ and 2 miles ${ }^{(29)}$. The use of a larger buffer size to examine neighbourhood food environments may better reflect the fact that a substantial proportion of people (particularly within the USA) do not live within walking distance of their primary food store. For example, Moore et $a l^{(30)}$ found that only $47 \%$ of US adults reported doing most of their food shopping within 1 mile of their home. In addition, Rose and Richards ${ }^{(31)}$ found that only $38 \%$ of low-income adults shopped for food $\leq 1$ mile from their home, with an additional $35 \%$ shopping within $1-5$ miles and $27 \%$ shopping $>5$ miles from home. Therefore, the buffer sizes used in the present study may generally capture the areas in which some of our adolescent participants (and/ or their families) do their food purchasing, but others may purchase food outside this area of exposure. In the present study, we were not able to measure specific food purchasing or eating behaviours in terms of the most relevant exposures in the food environment. This is an important limitation.

Overall, adolescence is an important developmental age accompanied by notable declines in a range of health behaviours. Numerous studies indicate that increased fast-food intake and eating away from home is associated with substantially lower diet quality among youth ${ }^{(32-34)}$. Our results suggest that neighbourhood environments surrounding the home are particularly associated with adolescents' consumption of SSB. Intervention strategies to promote healthy dietary patterns among adolescents are needed, some of which should include macro-level policy approaches. However, the decision-making processes that occur around dietary choices are highly complex, and nutrition promotion efforts will likely need to employ multiple approaches, including environmental availability and accessibility as well as other strategies, to be successful.

\section{Acknowledgements}

The present study was funded through NCI's Transdisciplinary Research in Energetics and Cancer Initiative (NCI
Grant 1 U54 CA116849-01), Principal Investigator: Robert Jeffery, PhD. Additional salary support was provided by NCI (K07CA126837). The content of this work is solely the responsibility of the authors and does not necessarily represent the official views of the National Cancer Institute. NCI did not play a role in designing the study, collecting the data or analysing/interpreting the results. There are no conflicts of interest. M.N.L. was responsible for drafting the manuscript and M.O.H. was responsible for analysing the data. A.F. was responsible for the GIS measurement. L.L. designed the original study, and all authors contributed to the editing and revising of the manuscript.

\section{References}

1. Larson NI, Story MT \& Nelson MC (2009) Neighborhood environments: disparities in access to healthy foods in the US. Am J Prev Med 36, 74-81.

2. Cummins S (2007) Commentary: investigating neighbourhood effects on health - avoiding the 'local trap'. Int $J$ Epidemiol 36, 355-357.

3. Beaulac J, Kristjansson E \& Cummins S (2009) A systematic review of food deserts, 1966-2007. Prev Chronic Dis 6, A105.

4. Khan LK, Sobush K, Keener D et al. (2009) Recommended community strategies and measurements to prevent obesity in the United States. MMWR Recomm Rep 58, 1-26.

5. Jago R, Baranowski T, Baranowski JC et al. (2007) Distance to food stores and adolescent male fruit and vegetable consumption: mediation effects. Int J Behav Nutr Phys Act 4, 35 .

6. Powell LM, Auld MC, Chaloupka FJ et al. (2007) Associations between access to food stores and adolescent body mass index. Am J Prev Med 33, S301-S307.

7. Austin SB, Melly SJ, Sanchez BN et al. (2005) Clustering of fast-food restaurants around schools: a novel application of spatial statistics to the study of food environments. $A m \mathrm{~J}$ Public Health 95, 1575-1581.

8. Davis B \& Carpenter C (2009) Proximity of fast-food restaurants to schools and adolescent obesity. Am J Public Health 99, 505-510.

9. Zenk SN \& Powell LM (2008) US secondary schools and food outlets. Health Place 14, 336-346.

10. Lytle LA (2009) Testing an ecological approach to examine the etiology of childhood obesity: The IDEA Study. Am J Commun Psychol 44, 338-349.

11. Forsyth A, Hearst MO, Oakes JM et al. (2008) Design and destinations: factors influencing walking and total physical activity. Urban Stud 45, 1973-1996.

12. Samuelson AC, Lytle LA, Farbakhsh K et al. (2010) The physical activity climate in Minnesota middle and high schools. J Phys Act Health (In the Press).

13. Lytle LA, Nichaman MZ, Obarzanek E et al. (1993) Validation of 24-hour recalls assisted by food records in third-grade children. The CATCH collaborative group. J Am Diet Assoc 93, 1431-1436.

14. Schakel S, Sievert Y \& Buzzard I (1988) Sources of data for developing and maintaining a nutrient database. J Am Diet Assoc 88, 1268-1271.

15. Willett W (1998) Nutritional Epidemiology, 2nd ed. New York: Oxford University Press.

16. Nelson MC \& Lytle LA (2009) Development and evaluation of a brief screener to estimate fast-food and beverage consumption among adolescents. J Am Diet Assoc 109, 730-734.

17. Kuczmarski RJ, Ogden C, Grummer-Strawn L et al. (2000) CDC Growth Charts: US. Advance Data from Vital and Health Statistics no. 314. Hyattsville, MD: NCHS. 
18. Wang YC, Gortmaker SL, Sobol AM et al. (2006) Estimating the energy gap among US children: a counterfactual approach. Pediatrics 118, e1721-e1733.

19. Liu GC, Wilson JS, Qi R et al. (2007) Green neighborhoods, food retail and childhood overweight: differences by population density. Am J Health Promot 21, 317-325.

20. Glanz K, Sallis JF, Saelens BE et al. (2007) Nutrition environment measures survey in stores (NEMS-S): development and evaluation. Am J Prev Med 32, 282-289.

21. Zenk SN, Schulz AJ, Israel BA et al. (2006) Fruit and vegetable access differs by community racial composition and socioeconomic position in Detroit, Michigan. Ethn Dis 16, 275-280

22. Sturm R \& Datar A (2005) Body mass index in elementary school children, metropolitan area food prices and food outlet density. Public Health 119, 1059-1068.

23. American Planning Association, Food System Planning Committee (2006) Food System Planning White Paper. Prepared for the APA's Legislative and Policy Committee. Washington, DC: APA.

24. Lytle LA (2009) Measuring the food environment: state of the science. Am J Prev Med 36, S134-S144.

25. Bader MD, Ailshire JA, Morenoff JD et al. (2010) Measurement of the local food environment: a comparison of existing data sources. Am J Epidemiol 171, 609-617.

26. Matthews SA, Moudon AV \& Daniel M (2009) Work group II: Using Geographic Information Systems for enhancing research relevant to policy on diet, physical activity, and weight. Am J Prev Med 36, S171-S176.
27. Bodor JN, Rose D, Farley TA et al. (2008) Neighbourhood fruit and vegetable availability and consumption: the role of small food stores in an urban environment. Public Health Nutr 11, 413-420.

28. Laraia BA, Siega-Riz AM, Kaufman JS et al. (2004) Proximity of supermarkets is positively associated with diet quality index for pregnancy. Prev Med 39, 869-875.

29. Jeffery RW, Baxter J, McGuire M et al. (2006) Are fast food restaurants an environmental risk factor for obesity? Int $J$ Behav Nutr Phys Act 3, 2.

30. Moore LV, Diez Roux AV, Nettleton JA et al. (2008) Associations of the local food environment with diet quality - a comparison of assessments based on surveys and geographic information systems: the multi-ethnic study of atherosclerosis. Am J Epidemiol 167, 917-924.

31. Rose D \& Richards R (2004) Food store access and household fruit and vegetable use among participants in the US Food Stamp Program. Public Health Nutr 7, 1081-1088.

32. French SA, Story M, Neumark-Sztainer D et al. (2001) Fast food restaurant use among adolescents. Int J Obes Relat Metab Disord 25, 1823-1833.

33. Schmidt M, Affenito SG, Striegel-Moore R et al. (2005) Fastfood intake and diet quality in black and white girls: the National Heart, Lung, and Blood Institute Growth and Health Study. Arch Pediatr Adolesc Med 159, 626-631.

34. Befort C, Kaur H, Nollen N et al. (2006) Fruit, vegetable, and fat intake among non-Hispanic black and non-Hispanic white adolescents: associations with home availability and food consumption settings. J Am Diet Assoc 106, 367-373. 